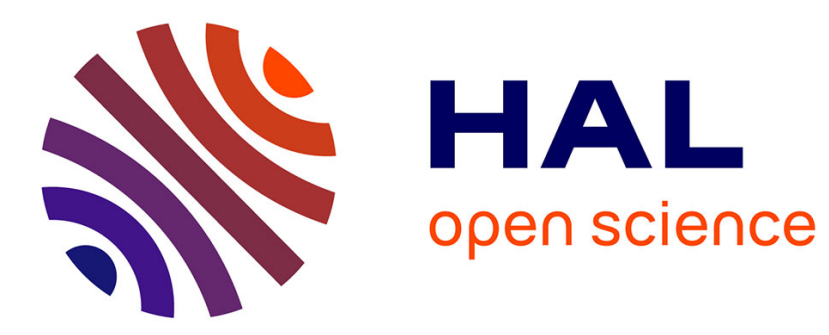

\title{
Access to Fluorenones Using Benzocyclopentynone Surrogate as Partner for the $[2+2+2]$ Cycloaddition Reaction
}

Anne-Doriane Manick, Bruno Salgues, Jean-Luc Parrain, Elena Zaborova, Frédéric Fages, Muriel Amatore, Laurent Commeiras

\section{To cite this version:}

Anne-Doriane Manick, Bruno Salgues, Jean-Luc Parrain, Elena Zaborova, Frédéric Fages, et al.. Access to Fluorenones Using Benzocyclopentynone Surrogate as Partner for the $[2+2+2]$ Cycloaddition Reaction. Organic Letters, 2020, 22 (5), pp.1894-1898. 10.1021/acs.orglett.0c00235 . hal-02873529

\section{HAL Id: hal-02873529 \\ https://hal.science/hal-02873529}

Submitted on 30 Sep 2020

HAL is a multi-disciplinary open access archive for the deposit and dissemination of scientific research documents, whether they are published or not. The documents may come from teaching and research institutions in France or abroad, or from public or private research centers.
L'archive ouverte pluridisciplinaire HAL, est destinée au dépôt et à la diffusion de documents scientifiques de niveau recherche, publiés ou non, émanant des établissements d'enseignement et de recherche français ou étrangers, des laboratoires publics ou privés. 


\section{Access to Fluorenones Using Benzocyclopentynone Surrogate as Partner for the [2 + 2+2] Cycloaddition Reaction}

Anne-Doriane Manick, Bruno Salgues, Jean-Luc Parrain, Elena Zaborova, Frédéric Fages, Muriel Amatore,* and Laurent Commeiras*

ABSTRACT: A convenient and versatile procedure for the straightforward synthesis of substituted fluorenones as valuable scaffolds is described under rhodium catalysis. The present $[2+2$ +2 ] cycloaddition reaction of diynes with 3-acetoxy or-3alkoxyindenones as surrogates of the highly reactive benzocyclopentynone $2 \pi$ partner allows the preparation of various fluorenonetype derivatives in good yields and provides an additional and tunable process for the generation of more challenging molecules with application in pharmaceutical, polymer, and material sciences.

9H-Fluoren-9-ones 1 are a significant class of organic scaffolds that combine a planar aromatic backbone and an exposed oxygen atom. Such compounds have been intensively described as important key synthetic intermediates in total synthesis $^{1}$ or potent biologically active compounds ${ }^{2}$ with important medical applications. ${ }^{3}$ Fluorenone derivatives also represent important precursors to synthesize a variety of organic electronic materials. ${ }^{4-6}$

In light of these aspects, many groups have contributed to the development of synthetic methods to prepare these privileged structures. They mainly include Friedel-Crafts acylation, ${ }^{7}$ radical cyclization, ${ }^{8}$ cascade reactions based on $\mathrm{C}-\mathrm{H}$ activation process, ${ }^{9}$ oxidative dehydrogenative couplings by dual $\mathrm{C}-\mathrm{H}$ functionalization, ${ }^{10}$ and transition-metalcatalyzed cyclization. ${ }^{11}$ Fluorenones could also be obtained through cycloaddition reactions, ${ }^{12}$ which does represent a powerful atom-economy route toward functionalized polycyclic compounds. Surprisingly, even if $[2+2+2]$ cycloaddition reactions are the most established strategies to access arene derivatives, only two elegant examples have been reported in the literature for the construction of fluorenones ${ }^{13}$ and sophisticated fluorenones-[9] helicenes ${ }^{14}$ (Scheme 1, (a) and (b)). Conceptually, a very intuitive strategy (Scheme 1, (c)) to prepare fluorenone moiety 1 would involve a metalcatalyzed $[2+2+2]$ cycloaddition reaction of two alkyne moieties $2(2 \pi+2 \pi$ partner $)$ and a five-membered ring containing a triple bond such as the hypothetic benzocyclopentynone 3 ( $2 \pi$ partner). Here, we anticipate that 3 -acetoxyor 3-alkoxy- $1 \mathrm{H}$-inden-1-one 4 , by reacting through its double bond, could be an alkyne surrogate for benzocyclopentynone 3. Indeed, the groups of Takeuchi, ${ }^{15}$ Tanaka, ${ }^{16}$ and Aubert and Vollhardt ${ }^{17}$ have shown that enol ethers and enol acetates can be considered as alkyne equivalents in metal-catalyzed $[2+2+$ 2] cycloaddition reactions to afford the corresponding substituted aromatic compound after rearomatization through
Scheme 1. Strategies for the Preparation of Fluorenone Scaffold via $[2+2+2]$ Cycloaddition Reactions
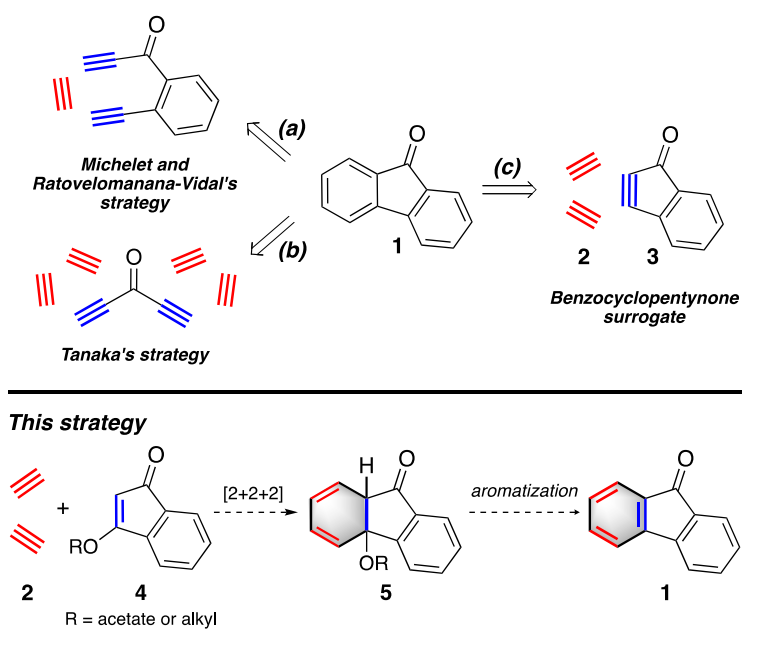

elimination of an alcohol or acetic acid molecule. Therefore, from a mechanistic point of view, this implies that the double bond of indenone 4 would first react as a regular $2 \pi$ partner leading to cycloadduct 5 . Then, because aromatization is the driving force of the $\beta$-elimination step, formation of the desired fluorenone 1 should occur. Herein, we report a new and 
straightforward route to the synthesis of fluorenone scaffolds 1 via rhodium-catalyzed $[2+2+2]$ cycloaddition reaction involving a hypothetic benzocyclopentynone 3 as original $2 \pi$ partner, providing a nice and attractive input for the existent synthetic toolbox.

To probe the feasibility of our strategy, the model reaction of diyne 2a bearing a gem-bis(methyl ester) tether and readily available 3 -acetoxy- $1 H$-inden-1-one $\mathbf{4 a}$ (ratio $\mathbf{2 a} / \mathbf{4 a}=1: 1$ ) was first examined under classical rhodium catalysis in anhydrous 1,2-dichloroethane (DCE) at $80{ }^{\circ} \mathrm{C}$. Because indenone 4a turned out to be poorly reactive as $2 \pi$ partner toward diyne $2 \mathrm{a}$, the latter was slowly introduced to the reaction mixture in order to avoid undesirable formation of cyclodimer $\mathbf{8 a}$ (see the SI for more detailed studies). ${ }^{18 a}$ In the presence of $[\mathrm{Rh}$ $\left.(\operatorname{cod})_{2}\right] \mathrm{BF}_{4}$ and racemic BINAP $^{19}$ ligand, the reaction proceeded smoothly with a complete conversion of diyne 2a to afford the desired fluorenone adduct 1 aa in $32 \%$ yield along with 6a (40\%) and the indene-1,3-dione 7 (27\%) (Table 1, entry 1). By increasing the catalyst loading to $20 \mathrm{~mol} \%$ the yields of $6 \mathbf{a}$ and 7 could be further decreased resulting in a

Table 1. Optimization of the Reaction Conditions
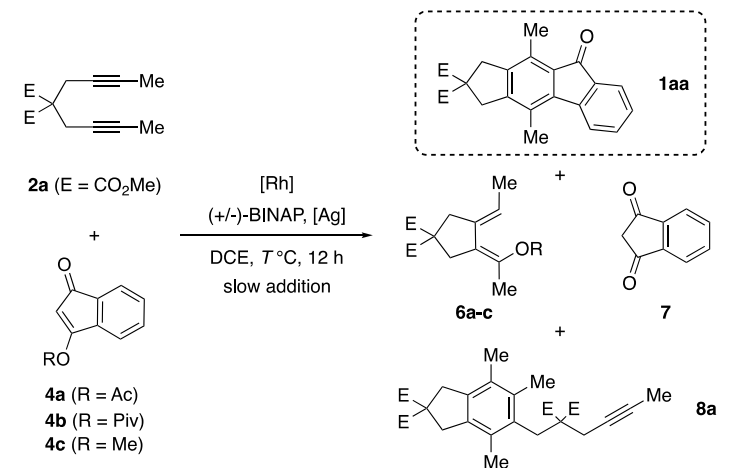

6a-c

7

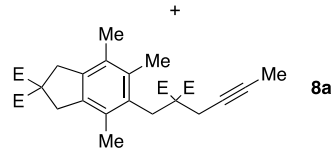

$\begin{array}{clclcl}\text { entry } & {[\mathrm{Rh}]^{a, b}(\mathrm{~mol} \%)} & \mathbf{4} & {[\mathrm{Ag}]^{c}} & \begin{array}{c}T \\ \left({ }^{\circ} \mathrm{C}\right)\end{array} & \begin{array}{c}\text { yield of 1aa/6/ } \\ 7 / 8 \mathbf{a}^{d}(\%)\end{array} \\ 1 & {\left[\mathrm{Rh}(\mathrm{cod})_{2}\right] \mathrm{BF}_{4}(10)} & \mathbf{4 a} & \text { none } & 80 & 32 / 40 / 27 / 0 \\ 2 & {\left[\mathrm{Rh}(\mathrm{cod})_{2}\right] \mathrm{BF}_{4}(20)} & \mathbf{4 a} & \text { none } & 80 & 39 / 12 / 10 / 0 \\ 3 & {\left[\mathrm{Rh}\left(\mathrm{C}_{2} \mathrm{H}_{4}\right)_{2} \mathrm{Cl}\right]_{2}(10)} & \mathbf{4 a} & \mathrm{AgBF}_{4} & 80 & 46 / 31 / 13 / 0 \\ 4 & {[\mathrm{Rh}(\mathrm{cod}) \mathrm{Cl}]_{2}(10)} & \mathbf{4 a} & \mathrm{AgBF}_{4} & 80 & 14 / 45 / 27 / 0 \\ 5 & {\left[\mathrm{Rh}\left(\mathrm{C}_{6} \mathrm{H}_{10}\right) \mathrm{Cl}\right]_{2}(10)} & \mathbf{4 a} & \mathrm{AgBF}_{4} & 80 & 79 / 20 / 0 / 0 \\ 6 & {\left[\mathrm{Rh}\left(\mathrm{C}_{6} \mathrm{H}_{10}\right) \mathrm{Cl}\right]_{2}(5)} & \mathbf{4 a} & \mathrm{AgBF}_{4} & 80 & 49 / 31 / 22 / 0^{e} \\ 7 & {\left[\mathrm{Rh}\left(\mathrm{C}_{6} \mathrm{H}_{10}\right) \mathrm{Cl}\right]_{2}(10)} & \mathbf{4 a} & \text { none } & 80 & 26 / 0 / 27 / 54 \\ 8 & {\left[\mathrm{Rh}\left(\mathrm{C}_{6} \mathrm{H}_{10}\right) \mathrm{Cl}\right]_{2}(10)} & \mathbf{4 a} & \mathrm{AgSbF}_{6} & 80 & 9 /-/-/-^{f} \\ 9 & {\left[\mathrm{Rh}\left(\mathrm{C}_{6} \mathrm{H}_{10}\right) \mathrm{Cl}\right]_{2}(10)} & \mathbf{4 a} & \mathrm{AgOTf} & 80 & - \\ 10 & {\left[\mathrm{Rh}\left(\mathrm{C}_{6} \mathrm{H}_{10}\right) \mathrm{Cl}\right]_{2}(10)} & \mathbf{4 a} & \mathrm{AgBF}_{4} & 50 & 29 / 34 / 20 / 0 \\ 11 & {\left[\mathrm{Rh}\left(\mathrm{C}_{6} \mathrm{H}_{10}\right) \mathrm{Cl}\right]_{2}(10)} & \mathbf{4 a} & \mathrm{AgBF}_{4} & \mathrm{rt} & 28 / 37 / 15 / 0 \\ 12^{g} & {\left[\mathrm{Rh}\left(\mathrm{C}_{6} \mathrm{H}_{10}\right) \mathrm{Cl}\right]_{2}(10)} & \mathbf{4 a} & \mathrm{AgBF}_{4} & 80 & 79 / 21 / 5 / 0^{f} \\ 13 & {\left[\mathrm{Rh}\left(\mathrm{C}_{6} \mathrm{H}_{10}\right) \mathrm{Cl}\right]_{2}(10)} & \mathbf{4 b} & \mathrm{AgBF}_{4} & 80 & 61 / 26 / 18 / 0 \\ 14 & {\left[\mathrm{Rh}\left(\mathrm{C}_{6} \mathrm{H}_{10}\right) \mathrm{Cl}\right]_{2}(10)} & \mathbf{4 c} & \mathrm{AgBF}_{4} & 80 & 44 / 0 / 26 / 30^{h} \\ 15^{i} & {\left[\mathrm{Rh}\left(\mathrm{C}_{6} \mathrm{H}_{10}\right) \mathrm{Cl}\right]_{2}(10)} & \mathbf{4 a} & \mathrm{AgBF}_{4} & 80 & 73 / 13 / 7 / 0 \\ 16^{j} & {\left[\mathrm{Rh}\left(\mathrm{C}_{6} \mathrm{H}_{10}\right) \mathrm{Cl}\right]_{2}(10)} & \mathbf{4 a} & \mathrm{AgBF}_{4} & 80 & 76 / 0 / 10 / 0\end{array}$

${ }^{a}$ See ref 19 for specification on rhodium source. ${ }^{b}[\mathrm{Rh}] /( \pm)$-BINAP $=$ $1: 1$ when using a cationic rhodium source and $[\mathrm{Rh}] /( \pm)$-BINAP $=$ $1: 2$ when using a neutral dimeric rhodium source. ${ }^{c}[\mathrm{Rh}] /[\mathrm{Ag}]=1: 2$ when $[\mathrm{Ag}]$ was used. ${ }^{d}$ Unless noted otherwise, full conversion of diyne 2a was observed. ${ }^{e}$ Conversion of diyne 2a was $90 \%$. ${ }^{f}$ Degradation was observed. ${ }^{g} 2.0$ equiv of crushed $4 \AA$ molecular sieves was used. ${ }^{h}$ Conversion of diyne 2 a was $75 \%$. ${ }^{i} 1.0$ equiv of $\mathrm{CaH}_{2}$ was used. ${ }^{j} 2.0$ equiv of $\mathrm{CaH}_{2}$ was used. more convenient purification (Table 1, entry 2). We next screened various neutral rhodium complexes in association with a silver salt ${ }^{20}$ and racemic BINAP as ligand (Table 1, entries 3-5). Pleasingly, the reaction catalyzed by the combination $\left[\mathrm{Rh}\left(\mathrm{C}_{6} \mathrm{H}_{10}\right) \mathrm{Cl}_{2} / \mathrm{AgBF}_{4} /( \pm)\right.$-BINAP formed the corresponding fluorenone adduct laa in $79 \%$ yield (Table 1, entry 5). Unfortunately, when the catalytic system loading was reduced in half, reaction efficiency and selectivity were altered (Table 1, entry 6). Interestingly, no lack of reactivity could be noted in the absence of the silver salt as the starting diyne $\mathbf{2 a}$ was fully consumed although leading to the undesired cyclodimer $\mathbf{8 a}$ as major compound (Table 1, entry 7), thus illustrating a less common feature for $\mathrm{AgBF}_{4}$ in this reaction process, probably through activation of partner 4 and possible decomposition to furnish dione 7. Finally, reactions in the presence of $\mathrm{AgSbF}_{6}$ or AgOTf occurred with deleterious side reactions (Table 1 , entries 8 and 9). Further screening of solvent and ligand revealed that DCE and racemic BINAP were the most effective for this reaction (see SI for more detailed studies). ${ }^{18 \mathrm{~b}}$ The selectivity of the reaction under our best conditions (Table 1, entry 5) was significantly influenced by the reaction temperature since fluorenone 1 aa could be isolated in only moderate yields of 29 and $28 \%$ at $50{ }^{\circ} \mathrm{C}$ and room temperature respectively (Table 1 , entries 10 and 11). Finally, strict removal of water traces did not show an improvement on the reaction outcome, and the desired product and byproducts ratios remained unchanged (Table 1 , entry 12). Because the formation of five-membered ring 1,3diene 6 byproducts would be the result of a rhodium-catalyzed carboxylative cyclization of diyne $2 \mathbf{a}$ in the presence of the released competitive carboxylic acid in the medium, as already reported by Tanaka and co-workers ${ }^{21}$ (see mechanistic discussion for more details, Scheme 3), the latter could be suppressed by changing the nature of the indenone derivative 4. Unfortunately, the use of indenone $\mathbf{4 b}$ as precursor of less acidic pivalic acid in the medium after the sequence $[2+2+2]$ cycloaddition/ $\beta$-elimination did not show any improvement (Table 1, entry 13). As expected, generation of methanol instead of acetic acid did not allow the 1,3-diene formation but the corresponding indenone $\mathbf{4 c}$ appeared less reactive in the desired cycloaddition process affording cycloadduct $\mathbf{1}$ aa in a moderate $44 \%$ yield with a large amount of cyclodimer 8a (Table 1, entry 14). Finally, the reaction proceeded smoothly using indenone $\mathbf{4 a}$ in the presence of a hydride source in the medium, resulting in an efficient quenching of the competitive carboxylic acid released during the course of the reaction ( 2 equiv for a complete suppression of the carboxylative cyclization, Table 1, entries 15 and 16). Because of a cleaner purification step, we chose to continue with $\mathrm{CaH}_{2}$ as a beneficial additive.

Under the previous optimized conditions (Table 1, entry 16), we next explored the scope and limitations of the reaction. We first examined the efficiency of this process with a range of diynes as summarized in Table 2. Diynes bearing different tethers were tested providing the desired fluorenone adducts in good to excellent yields up to $81 \%$ (Table 2, entries 1-3). Gratifyingly, in the special case of diyne $2 \mathrm{c}$ displaying a gembiscyano tether, the reaction was highly selective and the corresponding cycloadduct $\mathbf{1}$ ca could be isolated as the sole product (Table 2, entry 3). Dimethyl-substituted 3-acetoxyindenone $\mathbf{4 d}$ also afforded a good $51 \%$ yield when chosen as substrate for the reaction with diyne $\mathbf{2 a}$ (Table 2, entry 4). Using nonsubstituted diynes at the alkyne termini caused no 
Table 2. Rhodium-Catalyzed Synthesis of Substituted Fluorenones: Substrate Scope
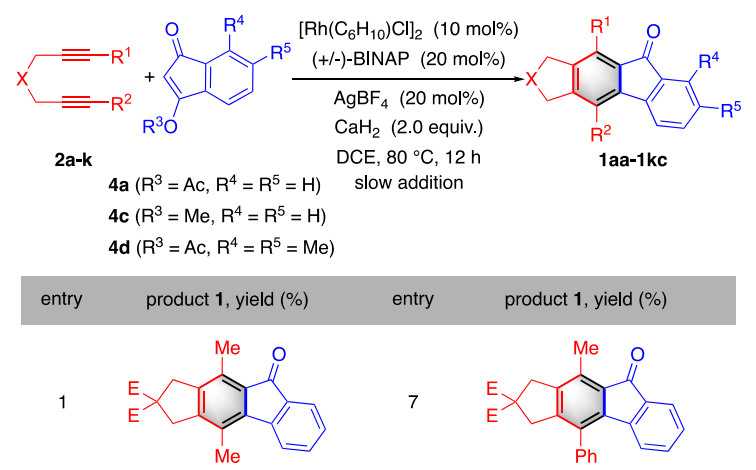

1aa $\left(\mathrm{E}=\mathrm{CO}_{2} \mathrm{Me}\right) 76 \%$

1fa $\left(\mathrm{E}=\mathrm{CO}_{2} \mathrm{Et}\right) 41 \%,{ }^{c}(1: 1)$ ratio $^{d}$

2

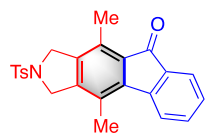

1 ba $54 \%$

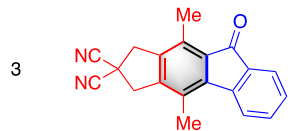

$81 \% a, b$

$\mathrm{Me}$

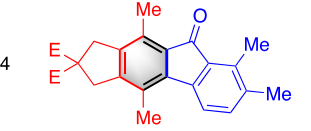

$\operatorname{1ad}\left(\mathrm{E}=\mathrm{CO}_{2} \mathrm{Me}\right) 51 \%$

5

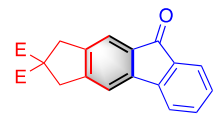

1da $\left(\mathrm{E}=\mathrm{CO}_{2} \mathrm{Me}\right) 67 \%$

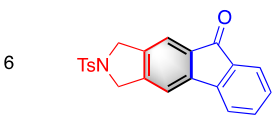

1ea $62 \%$

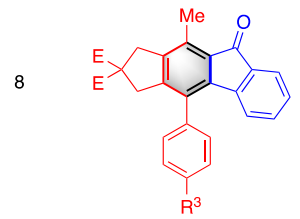

1ga $\left(\mathrm{E}=\mathrm{CO}_{2} \mathrm{Me}, \mathrm{R}^{3}=\mathrm{MeO}\right)$ $65 \%,{ }^{c}(1: 1)$ ratio $^{d}$ Tha $\left(\mathrm{E}=\mathrm{CO}_{2} \mathrm{Me}, \mathrm{R}^{3}=\mathrm{NO}_{2}\right)$ $54 \%,{ }^{c}(1: 1)$ ratio $^{d}$

9

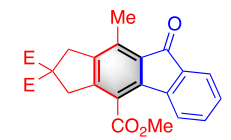

$1 \mathbf{i a}\left(\mathrm{E}=\mathrm{CO}_{2} \mathrm{Me}\right) 73 \%$

10

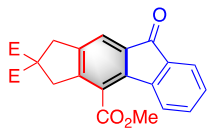

1 ja $\left(\mathrm{E}=\mathrm{CO}_{2} \mathrm{Me}\right)$ $56 \%,{ }^{c}(90: 10)$ ratio $^{d}$

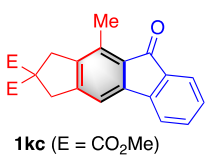

$36 \%,{ }^{f}(1: 1)$ ratio

${ }^{a}$ Fluorenone 1c was observed and isolated as the sole compound. ${ }^{b}$ Reaction was scaled up from 0.127 to $0.5 \mathrm{mmol}$ with a $71 \%$ yield and to $1 \mathrm{mmol}$ with a $66 \%$ yield. ${ }^{c}$ The corresponding yield refers to a mixture of both regioisomers that could be isolated as pure compounds from a complex mixture. ${ }^{d}$ The regioisomeric ratio was determined by ${ }^{1} \mathrm{H}$ NMR analysis of the crude mixture. ${ }^{e}$ Reaction was carried out with 3 -methoxyindenone $4 \mathrm{c} .{ }^{f}$ Only $36 \%$ yield of the above regioisomer could be isolated as pure compound from a complex mixture containing both regioisomers.

problem in this cycloaddition process (Table 2, entries 5 and 6). Diynes $\mathbf{2} \mathbf{f}-\mathbf{h}$ with different terminal groups such as phenyl and para-substituted phenyl (electron-donating and -withdrawing) were also tolerated, and satisfactory yields of fluorenones $\mathbf{1 f}-\mathbf{h}$ were produced although the reactions proved to be poorly regioselective (Table 2, entries 7 and 8). In contrast, the present cycloadditions exhibited an excellent regioselectivity when employing diynes $2 \mathbf{i}-\mathbf{j}$ possessing at least one methylester group at the alkyne terminus

(Table 2, entries 9 and 10). This clear trend would be explained by a strong directing effect of the ester group mainly through additional chelation of the rhodium center (see intermediate B, Scheme 3). The reaction of unsymmetrical diyne $2 \mathrm{k}$ with indenone $4 \mathrm{a}$ was also examined under standard conditions (Table 2, entry 11). According to the previous results, fluorenone $1 \mathrm{ka}$ should be obtained as major compound. However, no desired product could be observed and the reaction provided a complex mixture containing mainly the corresponding 1,3-diene with acetate incorporation and hydrolyzed indenone 7 . Because, competing carboxylative cyclization of diyne $\mathbf{2 k}$ appeared problematic in the presence of a carboxylic acid source, ${ }^{21}$ we envisioned an alternative approach in which indenone $4 \mathrm{a}$ was switched to indenone 4c bearing a methoxy group. As expected, the carboxylative competitive pathway was suppressed and the desired fluorenone $1 \mathrm{kc}$ could be isolated in a modest $36 \%$ yield and no regioselectivity.

The concept was also broadened to the synthesis of an anthracene type derivative 9 illustrating the potential application of this methodology for the generation of new $\pi$ conjugated systems with optical and electronic properties (Scheme 2). Cycloaddition of diyne 21 displaying a carbon

Scheme 2. Reaction of Diyne 21 with Indenone $4 c$ and Synthetic Transformation

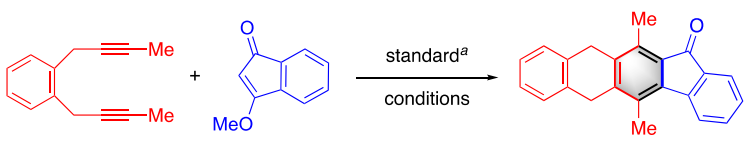

21

$4 c$

1 lc $41 \%$ yield

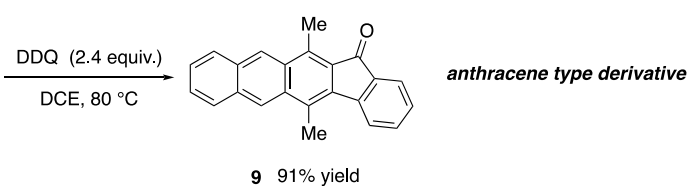

${ }^{a}$ Reactions were carried out under standard conditions as described in Table 2.

tether with indenone $\mathbf{4 c}$ proceeded smoothly to afford the corresponding fused polycyclic fluorenone 1lc with a satisfactory yield. Gratifyingly, the obtained cycloadduct could be easily oxidized to produce the targeted anthracene derivative 9.

A plausible reaction mechanism is depicted in Scheme 3. Fluorenone 1 would be obtained through the well-established rhodium-catalyzed $[2+2+2]$ cycloaddition mechanism. Oxidative coupling of the two alkyne moieties of diyne 2 would afford the common rhodacyclopentadiene intermediate $\mathbf{A}$. Subsequent insertion of indenone 4 would conduct to rhodacycle $\mathbf{B}$ stabilized by internal coordination of the enol ether group, the latter favored when indenone 4 is featuring a more coordinating acetate group. ${ }^{16}$ In the special case of diynes $2 \mathbf{i}$ and $2 \mathbf{j}$ bearing an ester group on the alkyne terminus, ${ }^{16}$ such additional coordination to the rhodium center would lead to an excellent regioselectivity. With unsymmetrical diynes, no discrimination would occur because of the existing competition between steric hindrance and beneficial coordination of the acetate group over ketone group (diynes $2 \mathbf{f}-\mathbf{h}$ and indenone $4 \mathrm{a}$ ) or the equivalent coordination mode displayed by the methoxy and ketone groups (diyne $2 \mathrm{k}$ and 
Scheme 3. Mechanistic Proposal

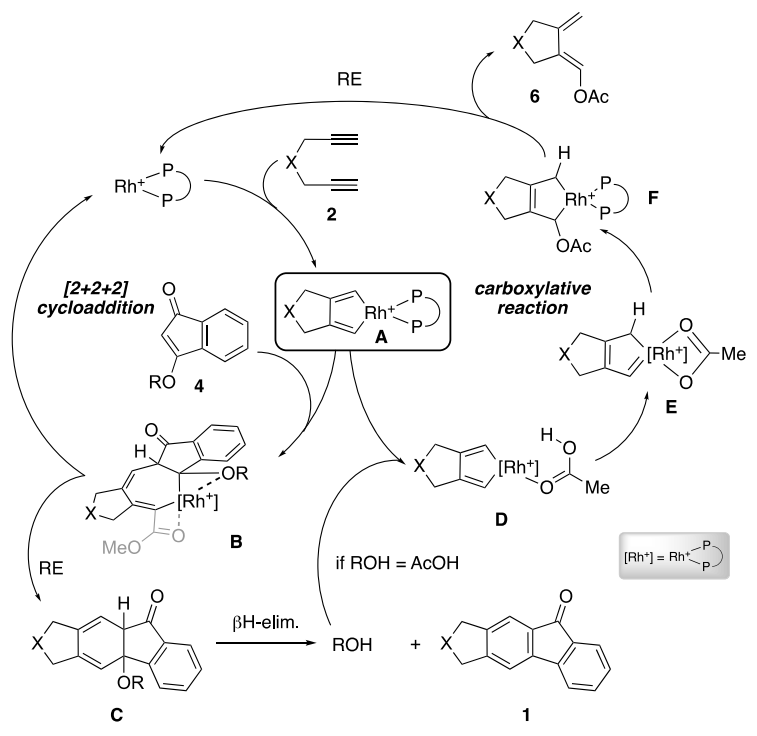

indenone 4c). Final reductive elimination and following rearomatization would furnish the corresponding fluorenone 1. Carboxylative cyclizations of 1,6- and 1,7-diynes using carboxylic acids have been previously accomplished under rhodium catalysis ${ }^{21}$ and these reactions would involve the addition of a $\mathrm{O}-\mathrm{H}$ bond on a metallacyclopentadiene intermediate. Under our reaction conditions, the released carboxylic acid would react with the shared rhodacyclopentadiene intermediate $\mathbf{A}$ to form a novel intermediate $\mathbf{E}$ bearing a carboxylate ligand after protonation of the metallacycle. Further evolution of this intermediate through acylation (formation of the $\mathrm{C}-\mathrm{O}$ bond) would generate a rhodacyclopentene intermediate F. Final reductive elimination forming the corresponding 1,3-diene as byproduct would end up the catalytic cycle.

In summary, we have designed a complementary methodology providing yet controlled access to substituted fluorenones in good yields as valuable scaffolds for the development of novel pharmaceuticals, dyes, polymers and ligands. The originality of this process, centered on a rhodiumcatalyzed $[2+2+2]$ cycloaddition, is based on the use of 3alkoxy- or 3-acetoxyindenones as surrogates of the highly reactive benzocyclopentynone $2 \pi$ partner. Importantly, this easily tunable and convergent methodology could enable the straightforward synthesis of more complex polycyclic fluorenone-type targets with defined properties from readily available starting materials. Further investigations to explore the full potential of this method and to reach more challenging higher value products are underway in our laboratory.

\section{ASSOCIATED CONTENT}

\section{Accession Codes}

CCDC 1977637-1977638 contain the supplementary crystallographic data for this paper. These data can be obtained free of charge via www.ccdc.cam.ac.uk/data request/cif, or by emailing data_request@ccdc.cam.ac.uk, or by contacting The Cambridge Crystallographic Data Centre, 12 Union Road, Cambridge CB2 1EZ, UK; fax: +44 1223336033.

\section{AUTHOR INFORMATION}

Corresponding Authors

Muriel Amatore - Aix Marseille Univ, CNRS, Centrale Marseille, iSm2, Marseille 13397, France; ๑ orcid.org/00000002-6455-5633; Email: muriel.amatore@univ-amu.fr

Laurent Commeiras - Aix Marseille Univ, CNRS, Centrale Marseille, iSm2, Marseille 13397, France; ๑ orcid.org/00000003-4331-6198; Email: laurent.commeiras@univ-amu.fr

Authors

Anne-Doriane Manick - Aix Marseille Univ, CNRS, Centrale Marseille, iSm2, Marseille 13397, France

Bruno Salgues - Aix Marseille Univ, CNRS, CINaM, UMR 7325, Marseille 13284, France

Jean-Luc Parrain - Aix Marseille Univ, CNRS, Centrale Marseille, iSm2, Marseille 13397, France

Elena Zaborova - Aix Marseille Univ, CNRS, CINaM, UMR 7325, Marseille 13284, France

Frédéric Fages - Aix Marseille Univ, CNRS, CINaM, UMR 7325, Marseille 13284, France; ㅇ orcid.org/0000-00032013-0710

Notes

The authors declare no competing financial interest.

\section{ACKNOWLEDGMENTS}

The project leading to this publication has received funding from Excellence Initiative of Aix-Marseille University A*MIDEX, a French "Investissement d'Avenir" program. This work was also supported by CNRS, MRES and AMU, which we gratefully acknowledge.

\section{REFERENCES}

(1) Shi, Y.; Gao, S. Tetrahedron 2016, 72, 1717.

(2) (a) Cone, M. C.; Melville, C. R.; Gore, M. P.; Gould, S. J. J. Org. Chem. 1993, 58, 1058. (b) Fan, C.; Wang, W.; Wang, Y.; Qin, G.; Zhao, W. Phytochemistry 2001, 57, 1255. (c) Wu, X. Y.; Qin, G. W.; Fan, D. J.; Xu, R. S. Phytochemistry 1994, 36, 477.

(3) Selected references: (a) Alcaro, S.; Artese, A.; Iley, J. N.; Maccari, R.; Missailidis, S.; Ortuso, F.; Ottanà, R.; Ragazzon, P.; Vigorita, M. G. Bioorg. Med. Chem. Lett. 2007, 17, 2509. (b) Lee, C.C.; Chang, D.-M.; Huang, K.-F.; Chen, C.-L.; Chen, T.-C.; Lo, Y.; Guh, J.-H.; Huang, H.-S. Bioorg. Med. Chem. 2013, 21, 7125. (c) Kawazoe, K.; Yutani, A.; Tamemoto, K.; Yuasa, S.; Shibata, H.; Higuti, T.; Takaishi, Y. J. Nat. Prod. 2001, 64, 588. (d) Li, Y.-C.; Huang, F.-M.; Lee, S.-S.; Lin, R.-H.; Chou, M.-Y.; Chang, Y.-C. J. Biomed. Mater. Res., Part B 2008, 84B, 58. (e) Lee, S.; Esteva-Font, C.; Phuan, P.-W.; Anderson, M. O.; Verkman, A. S. MedChemComm 2015, 6, 1278. (f) Kim, M. J.; Seo, Y.; Hwang, G. T. RSC Adv. 2014, 4, 12012 .

(4) Duan, Y.; Semin, S.; Tinnemans, P.; Cuppen, H.; Xu, J.; Rasing, T. Nat. Commun. 2019, 10, 4573. 
(5) (a) Usta, H.; Facchetti, A.; Marks, T. J. Org. Lett. 2008, 10, 1385. (b) Delbosc, N.; Yahya, W. Z. N.; Lemaitre, N.; Berson, S.; Fuchs, F.; Grévin, B.; Faure-Vincent, J.; Travers, J.-P.; Demadrille, R. RSC Adv. 2014, 4, 15236.

(6) Yuan, M.-S.; Wang, D.-E.; Xue, P.; Wang, W.; Wang, J.-C.; Tu,

Q.; Liu, Z.; Liu, Y.; Zhang, Y. Wang Chem. Mater. 2014, 26, 2467.

(7) Souibgui, A.; Gaucher, A.; Marrot, J.; Aloui, F.; MahuteauBetzer, F.; Ben Hassine, B.; Prim, D. Eur. J. Org. Chem. 2013, 2013, 4515. See also references cited therein.

(8) Zhu, H.; Chen, Z. Org. Lett. 2016, 18, 488. See also references cited therein.

(9) Selected references: (a) Chen, S.; Yu, J.; Jiang, Y.; Chen, F.; Cheng, J. Org. Lett. 2013, 15, 4754. (b) Li, B.-J.; Wang, H.-Y.; Zhu, Q.-L.; Shi, Z.-J. Angew. Chem., Int. Ed. 2012, 51, 3948. (c) Ravi Kumar, D.; Satyanarayana, G. Org. Lett. 2015, 17, 5894. (d) Zhao, J.; Yue, D.; Campo, M. A.; Larock, R. C. J. Am. Chem. Soc. 2007, 129, 5288.

(10) Shi, Z.; Glorius, F. Chem. Sci. 2013, 4, 829. See also references cited therein.

(11) Selected references: (a) Marquise, N.; Dorcet, V.; Chevallier, F.; Mongin, F. Org. Biomol. Chem. 2014, 12, 8138. (b) Waldo, J. P.; Zhang, X.; Shi, F.; Larock, R. C. J. Org. Chem. 2008, 73, 6679.

(12) Selected examples based on Diels-Alder reaction: (a) Pünner, F.; Schieven, J.; Hilt, G. Org. Lett. 2013, 15, 4888. (b) Rodriguez, D.; Martínez-Esperon, M. F.; Navarro-Vázquez, A.; Castedo, L.; Domínguez, D.; Saá, C. J. Org. Chem. 2004, 69, 3842. (c) Domino sequence including [3+3] cycloaddition: Reim, S.; Lau, M.; Langer, P. Tetrahedron Lett. 2006, 47, 6903. (d) Formal $[4+4+1]$ cycloaddition: Li, Y.; Xu, H.; Fu, L.; shi, Q.; jiang, B.; Tu, S. Chin. J. Chem. 2013, 31, 737.

(13) Ye, F.; Haddad, M.; Michelet, V.; Ratovelomanana-Vidal, V. Org. Lett. 2016, 18, 5612 .

(14) (a) Sawada, Y.; Furumi, S.; Takai, A.; Takeuchi, M.; Noguchi, K.; Tanaka, K. J. Am. Chem. Soc. 2012, 134, 4080. (b) Tanaka, K.; Fukawa, N.; Suda, T.; Noguchi, L. Angew. Chem., Int. Ed. 2009, 48, 5470.

(15) Kezuka, S.; Tanaka, S.; Ohe, T.; Nakaya, Y.; Takeuchi, R. J. Org. Chem. 2006, 71, 543.

(16) (a) Hara, H.; Hirano, M.; Tanaka, K. Org. Lett. 2008, 10, 2537.

(b) Hara, H.; Hirano, M.; Tanaka, K. Tetrahedron 2009, 65, 5093.

(c) Aida, Y.; Tooriyama, S.; Kimura, Y.; Hara, H.; Shibata, Y.; Tanaka, K. Eur. J. Org. Chem. 2016, 2016, 132.

(17) Lebœuf, D.; Iannazzo, L.; Geny, A.; Malacria, M.; Vollhardt, K. P. C.; Aubert, C.; Gandon, V. Chem. - Eur. J. 2010, 16, 8904.

(18) (a) One pot reactions led to 1:1 mixtures of cycloadduct 1aa and cyclodimer $8 \mathbf{a}$ in association with diketone 7 and or without diene $\mathbf{6 a}$, with a complete conversion of diyne $\mathbf{2 a}$. (b) See the SI for more detailed solvent and ligand screening.

(19) Specifications on rhodium sources and abbreviations: cod, 1,5cyclooctadiene; $\mathrm{C}_{6} \mathrm{H}_{10}, 1,5$-hexadiene; $( \pm)$-BINAP, ( \pm )-2,2'-bis(diphenylphosphino)-1,1'-binaphthyl.

(20) Kondoh, A.; Yorimitsu, H.; Oshima, K. J. Am. Chem. Soc. 2007, 129, 6996.

(21) Tanaka, K.; Saitoh, S.; Hara, H.; Shibata, Y. Org. Biomol. Chem. 2009, 7, 4817 